\title{
Prevalence of gastrointestinal parasites in cattle and sheep in three municipalities in the Colombian Northeastern Mountain
}

\author{
Juan Carlos Pinilla León ${ }^{1}$, Nelson Uribe Delgado² and Angel Alberto Florez ${ }^{1}$
}

1. Department of Veterinary Medicine, University of Santander, Faculty of Exact, Natural and Agricultural Sciences, Animal Science Research Group, Bucaramanga, Colombia; 2. Department of Parasitology, Industrial University of Santander, Faculty of Health, Research Group in Molecular Epidemiology, Bucaramanga, Colombia.

Corresponding author: Juan Carlos Pinilla León, e-mail: j.pinilla@mail.udes.edu.co Co-authors: NUD: nelson_uribe@hotmail.com, AAF: a.florez@mail.udes.edu.co

Received: 17-08-2018, Accepted: 22-11-2018, Published online: 08-01-2019

doi: 10.14202/vetworld.2019.48-54 How to cite this article: Pinilla León JC, Delgado NU, Florez AA (2019) Prevalence of gastrointestinal parasites in cattle and sheep in three municipalities in the Colombian Northeastern Mountain, Veterinary World, 12(1): 48-54.

\begin{abstract}
Aim: The study was conducted to determine the prevalence of gastrointestinal (GI) parasites in cattle and sheep from three municipalities in the Colombian Northeastern Mountain.

Materials and Methods: Overall, 200 fecal samples were collected directly from the rectum in cattle and sheep. The presence of helminths eggs and coccidial oocysts in fecal samples was detected using McMaster and Dennis techniques. Identification of eggs or oocysts was done on the basis of morphology and size of the eggs or oocysts.

Results: The global prevalence of GI parasites was 56.3\%. Regarding the prevalence by municipalities, there was no statistical association ( $>0.05)$, indicating that the prevalence was similar in the three municipalities. The prevalence of parasitic infection was higher in sheep $(63 \%)$ as compared to that of cattle $(50.5 \%)$, but the difference was nonsignificant $(\mathrm{p}>0.05)$. The most prevalent parasites were Eimeria spp., Fasciola hepatica, and Strongylida order. Regarding the results for Eimeria spp., different degrees of positivity were observed, but there was no statistical association $(\mathrm{p}>0.05)$ with respect to the age group. Likewise, there was no statistical association $(\mathrm{p}>0.05)$ between the prevalence for Strongylida order and F. hepatica with respect to the age group.

Conclusion: Cattle and sheep in Colombian Northeastern Mountain were infected with helminths and coccidia. The prevalence values of GI parasites were moderate in both species warranting treatment. The presence of $F$. hepatica represents a risk factor to health public. Future studies are required to evaluate the parasitic dynamics throughout the year and the impact on animal production.
\end{abstract}

Keywords: cattle, gastrointestinal parasites, prevalence, sheep.

\section{Introduction}

Gastrointestinal (GI) parasitism is a disease caused by different genera of parasites that inhabit the digestive tract of cattle and sheep, causing inappetence, anemia, diarrhea, poor growth, and economic losses in the herds. Basically, GI parasitism in cattle and sheep is caused by helminths and protozoa [1]. Eimeria spp. is a protozoa belonging to the phylum Apicomplexa, family Eimeriidae that parasitize poultry, ruminants, equines, and rabbits, which causes bovine and ovine coccidiosis [1]. Helminthes are parasites that cause parasitic gastroenteritis in cattle and sheep. Among the nematodes, the most important and prevalent genera worldwide are those belonging to the Strongylida order, especially in tropical zones [2]. Fasciola hepatica is a trematode parasite affecting cattle, sheep, and

Copyright: Pinilla León, et al. Open Access. This article is distributed under the terms of the Creative Commons Attribution 4.0 International License (http://creativecommons.org/licenses/ by/4.0/), which permits unrestricted use, distribution, and reproduction in any medium, provided you give appropriate credit to the original author(s) and the source, provide a link to the Creative Commons license, and indicate if changes were made. The Creative Commons Public Domain Dedication waiver (http:// creativecommons.org/publicdomain/zero/1.0/) applies to the data made available in this article, unless otherwise stated. occasionally a man, which requires an intermediate host for their transmission. In Colombia, the national prevalence for $F$. hepatica in bovines is $25 \%$, with ranges between $25 \%$ and $80 \%$ in the Boyacá, Nariño, and Cundinamarca states [3]. Paramphistomum spp., Cotylophoron spp., and Calicophoron spp. are paramfistomids of veterinary importance, responsible for paramfistomosis, diagnosed in bovines, buffaloes, camelids, goats, and sheep [4].

The municipalities of Encino, Duitama, and Belen are located in the Northeastern Colombian Mountain. It is an agricultural region with traditional and small-scale livestock farms, being the cattle and sheep husbandry one of the most important components of the local economy. This region is notorious for its small dairy industry; however, 90\% of the farms are dedicated to dual purpose (beef and milk). According to ICA's vaccination records, the animal population census for the three municipalities was 15,000 heads [5].

In Colombia, there is very little epidemiological information on GI parasitism in cattle and sheep, mainly in the Eastern Mountain of the country, and for this reason, the aim was to determine the prevalence of GI parasites in cattle and sheep in the municipalities 
of Encino, Santander state, and Duitama and Belen, Boyaca state, Colombia.

\section{Materials and Methods}

Ethical approval

This research was approved by the Institutional Ethical Committee of the University of Santander and Industrial University of Santander, Colombia.

\section{Study area}

The study was conducted in the municipalities of Encino $\left(6^{\circ} 08^{\prime} 16^{\prime \prime} \mathrm{N}-73^{\circ} 05^{\prime} 53^{\prime \prime} \mathrm{O}\right)$ in the state of Santander and Duitama municipality $\left(5^{\circ} 49^{\prime} 19^{\prime \prime} \mathrm{N}-73^{\circ} 01^{\prime} 47^{\prime \prime} \mathrm{O}\right)$ and Belen municipality $\left(5^{\circ} 59^{\prime} 22^{\prime \prime} \mathrm{N}-72^{\circ} 54^{\prime} 44^{\prime \prime} \mathrm{O}\right)$ in the state of Boyaca, Colombia (Figure-1). Bioclimatic characteristics of the region are a mean annual temperature of $15^{\circ} \mathrm{C}$, with little weather variation along the year. Altitude is between 1850 and $4200 \mathrm{msl}$ and mean annual rainfall is $1815 \mathrm{~mm}$, with $87 \%$ of relative humidity $[6,7]$.

\section{Study design and sampling}

A random sampling, descriptive and transversal, was designed. 34 traditional and small-scale livestock farms were visited between October 2017 and February 2018, with a predominance of dairy breeds. The grazing management system and concentrated foods were followed in the animals. The average of animals per farm ranges from 30 to 35 . Using the formula for known populations [8], with an expected prevalence of $25 \%$ [9], and a confidence level of $95 \%$ with $6 \%$ of associated maximum error, 200 fecal samples were determined. 6-8 fecal samples were collected from each farm examined. Animals were categorized according to the age in: $<12$ months, 12-24 months, and $>24$ months.

\section{Collection and examination of fecal samples}

The study was conducted on 200 animals (103 cattle and 97 sheep) of small dairy farm. The fecal samples were collected randomly. Approximately $5-10 \mathrm{~g}$ of feces were collected directly from the rectum from each bovine and sheep, using previously labeled polyethylene bags. Samples were refrigerated and processed in the Investigation Research Laboratory of the Parasitology of the Industrial University of Santander. The stool samples were cultivated at room temperature in Petri dishes using $20 \mathrm{~mL}$ of $2.5 \%$ potassium dichromate solution for $24 \mathrm{~h}$ and later processed by the McMaster technique to determine the oocysts per gram (OPG) of feces and eggs per gram (EPG) of feces. The numbers of OPG and EPG were calculated with a detection level of 50 (two chambers) which is the standardized factor for this technique [10]. The Modified Dennis technique [11] was employed to detect the heavy F. hepatica and Paramphistomum spp. eggs. The oocysts and eggs of parasites were identified from their morphological characters, using a light optical microscope with a magnification of $10 \times$ and $40 \times$.

\section{Statistical analysis}

The GI parasitism prevalence results were analyzed by descriptive statistics and the Chi-square test to determine the analyzed variables. Calculations were made using the SPSS version 21 [12].

\section{Results}

The overall prevalence of GI parasites in the three municipalities was $56.5 \%(113 / 200)$. No statistical association was found $\left(\chi^{2}=4.9 ; p>0.05\right)$ between prevalence values in the three municipalities: $54.5 \%$ (42/77) in Encino, 59\% (59/100) in Belen, and 52.1\% $(12 / 23)$ in Duitama. According to these results, the prevalence is present in similar proportions in the three municipalities of the Santander and Boyaca state, Colombia. Regarding to results in cattle and sheep, the prevalence of GI parasites in cattle was $50.4 \%$ $(52 / 103)$ and $62.9 \%(61 / 97)$ in sheep. No statistical association was found $\left(\chi^{2}=2.7 ; p>0.05\right)$ between prevalence values in the two examined species. According to these results, the prevalence is present in similar proportions in cattle and sheep. With respect to the prevalence of GI parasites and sex of the animals, different degrees of parasitism were observed in female and male, but no statistical association was found $(p>0.05)$ with respect to the sex.

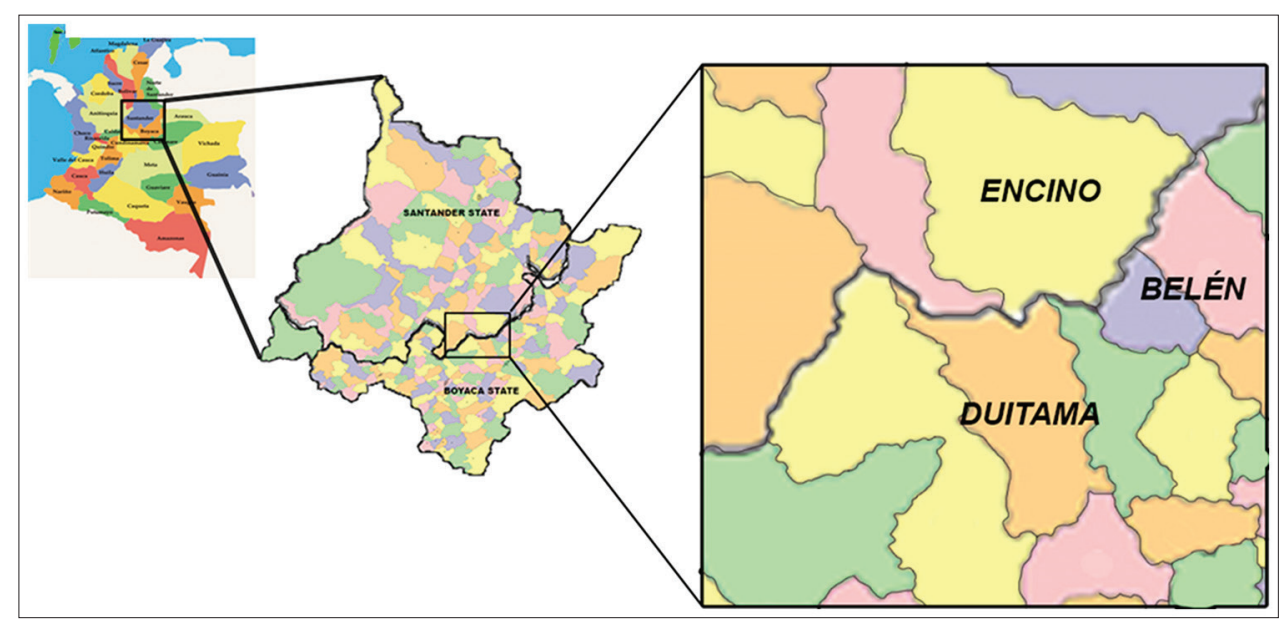

Figure-1: The political map of Colombia (left) and the study area (middle and right) with the three municipalities (Encino, Duitama, and Belen). 
Table-1: Prevalence and intensity of infection of GI parasites in cattle and sheep from the three municipalities.

\begin{tabular}{|c|c|c|c|c|}
\hline \multirow[t]{2}{*}{ Parasite } & \multicolumn{2}{|c|}{ Cattle $(n=103)$} & \multicolumn{2}{|c|}{ Sheep $(n=97)$} \\
\hline & Positive (\%) & $\begin{array}{c}\text { Intensity of infection } \\
\text { (EPG-OPG) }\end{array}$ & Positive (\%) & $\begin{array}{c}\text { Intensity of infection } \\
\text { (EPG-OPG) }\end{array}$ \\
\hline Eimeria spp. & $18(17.4)$ & 820 & $30(30.9)$ & 1270 \\
\hline Strongylida* & $17(16.5)$ & 150 & 31 (31.9) & 385 \\
\hline Fasciola hepatica & $23(22.3)$ & - & $14(14.4)$ & - \\
\hline Paramphistomum spp. & $1(0.97)$ & - & $2(2.06)$ & - \\
\hline Strongyloides spp. & $4(3.8)$ & 110 & $3(3.1)$ & 333 \\
\hline Moniezia spp. & $1(0.97)$ & - & $7(7.21)$ & - \\
\hline Trichuris spp. & $0(0)$ & 0 & $2(2.06)$ & 75 \\
\hline
\end{tabular}

*Reported as order; Fasciola hepatica, Paramphistomum spp., Moniezia spp. were not counted, EPG=Eggs per gram of feces, $\mathrm{OPG}=$ Oocysts per gram of feces

Table-2: Comparison between prevalence of Eimeria spp. infection and age group in cattle and sheep.

\begin{tabular}{lccc}
\hline \multirow{2}{*}{ Age group } & Cattle & & Sheep \\
\cline { 2 - 2 } & Positive (\%) & & Positive (\%) \\
\hline$<12$ months & $4(23.5)$ & & $16(48.5)$ \\
$12-24$ months & $3(50)$ & $8(24.2)$ \\
$>24$ months & $11(15.3)$ & & $6(40)$ \\
Total & $18(17.4)$ & & $30(30.9)$ \\
Chi-square & $\chi^{2}=4.6 ; \mathrm{p}=0.09$ & & $\chi^{2}=4.2 ; \mathrm{p}=0.1$ \\
\hline
\end{tabular}

No statistically significant $(p>0.05)$

Table-1 shows the seven parasite genera found in the study, being F. hepatica (22.3\%), Eimeria spp. (17.4\%), and Strongylida order (16.5\%) the most prevalent in cattle, while in sheep, the most prevalent values were found in Strongylida order (31.9\%) followed by Eimeria spp. (30.9\%) and F. hepatica (14.4\%). As for the intensity of infection, Eimeria spp. showed the highest level (820 and 1270 OPG) in cattle and sheep, respectively, followed by Strongylida order (150 and 385 EPG) in cattle and sheep, respectively. F. hepatica, Paramphistomum spp., and Moniezia spp., were not counted. The genera of nematodes and trematodes were identified by the morphology and size of their eggs [13].

Table-2 shows the comparison (Chi-square test) between positive percentages of Eimeria spp. parasitism and age of the animals. Different degrees of parasitism were observed in cattle and sheep, but no statistical association was found $(\mathrm{p}>0.05)$ with respect to the age group. Although all group showed infection by coccidian infection, cattle and sheep $>24$ months showed lower prevalence $(15.3 \%$ and $40 \%)$, respectively, than those under 12 months $(23.5 \%$ and $48.5 \%)$.

Table-3 shows the comparison (Chi-square test) between positive percentages of trematodes and cestodes parasitism and age of the animals. Different degrees of parasitism were observed in cattle and sheep, but no statistical association was found $(\mathrm{p}>0.05)$ with respect to the age group. All group showed infection by $F$. hepatica in cattle, but all the animals $<24$ months did not evidence excretion of Paramphistomum spp. eggs, while cattle $>12$ months did not evidence excretion of Moniezia spp. eggs. Sheep did not show excretion of Paramphistomum spp. eggs in $<12$ months animals. Table-4 shows prevalence values for the nematodes observed during the study. The parasites of the Strongylida order presented the highest prevalence in cattle and sheep $(17.9 \%$ and $38.3 \%)$, respectively, followed by the genus Strongyloides (4.2\% and 3.7\%), respectively. Trichuris spp. eggs were not found in fecal samples of cattle, while in sheep, two animals $(2.4 \%)<12$ months showed infection by this parasite. The comparison (Chi-square test) between positive nematode values and age group did not revealed statistical ( $>0.05)$ association between prevalence of parasite of the Strongylida order, Strongyloides spp., and Trichuris spp. and the age of the animals (Table-4).

\section{Discussion}

The GI parasitism is one of the major health problems affecting the productivity of the cattle and sheep in worldwide [14]. The presence of GI parasites in cattle and sheep depends greatly on predisposing environmental factors such as temperature and humidity. This has been observed in some parasites of the Strongylida order, which prevail in cold climates or tropical conditions [15]. The general prevalence $(56.3 \%)$ of GI parasites agrees with the findings of Colina et al. [16], who reported high prevalence in cattle in different regions of Peru with climatic conditions similar to those of Encino, Duitama, and Belen municipalities. Possibly, the environmental characteristics, reproductive stage, sex of the animal, as well as the pasture and agricultural practices in the farms have been predisposing factors for the high parasite prevalence in the cattle and sheep under study. These factors play a determinant role in the presence of the infective stages, favoring the developing of the reproductive cycles and the viability of eggs and larvae, which, in turn, depend on the season of the year, the age, and the immune status of the host [16].

The prevalence found in the three municipalities was similar, since the temperatures and humidity conditions in the zone, the type of vegetation, the management in most of the farms, sanitary programs, and management of pastures in the control of infectious agents are very much the same in the three municipalities. 
Table-3: Comparison between the prevalence of Trematoda and Cestoda parasitism and age group in cattle and sheep.

\begin{tabular}{lccc}
\hline Age group & Fasciola hepatica Positive (\%) Paramphistomum spp. Positive (\%) Moniezia spp. Positive (\%) \\
\hline Cattle $(\mathrm{n}=103)$ & $2(11.7)$ & $0(0)$ & $1(5.8)$ \\
$<12$ months & $1(16.6)$ & $0(0)$ & $0(0)$ \\
$12-24$ months & $20(27.7)$ & $1(1.4)$ & $0(0)$ \\
$>24$ months & $23(22.3)$ & $1(0.97)$ & $1(0.97)$ \\
Total & $\chi^{2}=2.3 ; \mathrm{p}=0.3$ & $\chi^{2}=0.3 ; \mathrm{p}=0.8$ & $\chi^{2}=4.6 ; \mathrm{p}=0.9$ \\
Chi-square & $5(15.1)$ & $0(0)$ & $4(12.1)$ \\
Sheep $(\mathrm{n}=97)$ & $8(24.2)$ & $1(3)$ & $1(3)$ \\
$<12$ months & $1(6.6)$ & $1(6.6)$ & $2(13.3)$ \\
$12-24$ months & $14(14.4)$ & $2(2.06)$ & $7(7.2)$ \\
$>24$ months & $\chi^{2}=2.4 ; \mathrm{p}=0.3$ & $\chi^{2}=1.9 ; \mathrm{p}=0.3$ & $\chi^{2}=2.2 ; \mathrm{p}=0.3$ \\
Total & &
\end{tabular}

No statistically significant $(p>0.05)$

Table-4: Comparison between prevalence of Nematoda parasitism and age group in cattle and sheep.

\begin{tabular}{|c|c|c|c|}
\hline Age group & Strongylida* Positive (\%) & Strongyloides spp. Positive (\%) & Trichuris spp. Positive (\%) \\
\hline \multicolumn{4}{|l|}{ Cattle $(n=103)$} \\
\hline$<12$ months & $2(11.8)$ & $1(5.9)$ & $0(0)$ \\
\hline $12-24$ months & $2(33.3)$ & $0(0)$ & $0(0)$ \\
\hline$>24$ months & $13(18.1)$ & $3(4.2)$ & $0(0)$ \\
\hline Total & $17(16.5)$ & $4(3.8)$ & $0(0)$ \\
\hline Chi-square & $\chi^{2}=1.4 ; p=0.5$ & $\chi^{2}=0.38 ; p=0.8$ & $\chi^{2}=0 ; p=0$ \\
\hline \multicolumn{4}{|l|}{ Sheep $(n=97)$} \\
\hline Age group & Strongylida* Positive (\%) & Strongyloides spp. Positive (\%) & Trichuris spp. Positive (\%) \\
\hline$<12$ months & $12(36.4)$ & $1(3)$ & $2(6.1)$ \\
\hline $12-24$ months & $16(48.5)$ & $1(3)$ & $0(0)$ \\
\hline$>24$ months & $3(20)$ & $1(6.7)$ & $0(0)$ \\
\hline Total & 31 (31.9) & $3(3.1)$ & $2(2.06)$ \\
\hline Chi-square & $\chi^{2}=3.6 ; p=0.1$ & $\chi^{2}=0.45 ; p=0.8$ & $\chi^{2}=2.9 ; p=0.22$ \\
\hline
\end{tabular}

*Reported as order; no statistically significant $(p>0.05)$

The GI parasites in cattle and sheep are considered one of the most important in tropical herds, since they reduce weight gain and cause high morbidity and mortality in young animals $[1,17]$. The present study found that $F$. hepatica was most prevalent parasite in cattle $(22.3 \%)$ followed by Eimeria spp. (17.4\%) and parasite genera grouped under the Strongylida order $(16.5 \%)$, while in sheep, the Strongylida order was most prevalent $(31.9 \%)$. These results agree with those by Orjuela et al. [18] who reported $26.8 \%$ of coccidian infection in cattle of the North Coast of Colombia. However, these results differ from those reported by Pinilla et al. [19] who found high prevalence (77.9\%) of Eimeria spp. in cattle of Aguachica and Rio de Oro municipalities, Cesar state, while Diaz de Ramirez et al. [17] reported 53\% prevalence in cattle from Trujillo state, Venezuela, and $86.01 \%$ prevalence in cattle from Yucatan state, Mexico [20,21]. Regarding to prevalence by Eimeria spp. in sheep, the result differs with those by Ensuncho-Hoyos et al. [22], DíazAnaya et al. [23], Pulido-Medellín et al. [24], who reported prevalence $81.6 \%, 94.4 \%$, and $63 \%$, respectively, in Cordoba and Boyaca state, Colombia. The mean intensity of infection for Eimeria spp. found in this study (820 OPG and 1270 OPG) in cattle and sheep, respectively, is considered moderate [15], it is inferred that could be caused by immunosuppression in the animals due to factors such as stress associated with overpopulation, transportation, and herd movements [25]. The coccidia infection in bovine and sheep could be due to their ability to adapt to different climatic conditions as well as for pasture management and contamination of water by parasitized adult cattle [26]; however, the low prevalence found in this study could be associated with the absence of risk factors, such as time of the year (sampling time), low rainfall in the area, size of the farm (200-300 bovines), and period (rainy season) [15].

Regarding to Eimeria spp., prevalence and age of the animals indicated that the infection in cattle and sheep occurs in any period during life and with higher excretion of oocysts in young animals (under than 24 months). The results obtained in cattle agree from those reported by Díaz de Ramírez et al. [17] and Tomczuk et al. [27] who found higher excretion of oocysts in young animals, while the infection in adult decreases. This is attributed to a considerable percentage of calves excreting oocysts during their $1^{\text {st }}$ month of life, and as most bovine Eimeria species have prepatent periods ranging from 2 to 3 weeks, calves most ingest a sufficient amount of sporulated oocysts to establish a patent infection in the herd. In the present study, infected adult cattle and sheep $(15.3 \%$ and $40 \%$ ), respectively, could become as asymptomatic 
host and potential sources of infection for calves and lambs, as they become infected when inoculated with sporulated oocysts by water, or licking the hair of animals with contaminated feces [28].

The prevalence values found for $F$. hepatica in cattle $(22.3 \%)$ and sheep (14.4\%) agree from those reported by other studies conducted in Colombia, reporting a national prevalence of $25 \%$, using coprological techniques [3]. Furthermore, the results obtained agree from those reported by Soca-Pérez et al. [29], Ticona et al. [30], and Gauta et al. [31], who reported medium and high prevalence values in farms from Cuba, Peru, and Venezuela, respectively. However, the results obtained in this study differ with those reported by other authors, who found lower prevalence values in cattle from different Costa Rica regions, Quindio and Cesar state, Colombia, respectively $[32,33]$. Furthermore, the result differs with those reported by Pulido-Medellin et al. [24], who determined lower prevalence values in sheep from Toca, Boyaca. Although there are no previous studies on prevalence and condemnation of livers from animals coming from the study zone, the medium prevalence values for $F$. hepatica found could be due to the interaction between susceptible animals and intermediate hosts who require special climatic conditions for their survival [29]. Moreover, the present study was designed as transversal and conducted in a dry season; this means that the dynamics of the parasite in other seasons of the year is not known.

According to the classification indicated by Valderrama [34] to define the F. hepatica endemicity area, the municipalities under study are considered as mesoendemic zones (10-50\% prevalence). This region is located at high altitudes (1800-3500 masl), with low temperatures $\left(13-18^{\circ} \mathrm{C}\right)$, and mean precipitation rates between $1130 \mathrm{~mm}$ and $2500 \mathrm{~mm}$, which are favorable climatological characteristics for the presence of intermediate hosts. Therefore, breeding in grass favors the presence of the parasite, since the animals have direct contact with the infecting form [34]. The ideal temperature for the trematode cycle should be between $10^{\circ} \mathrm{C}$ and $30^{\circ} \mathrm{C}$, with the presence of rain for 3 or more months a year. However, the temperature and humidity determine the seasonality of the disease [15]. Therefore, the characteristics of the region studied are highly favorable for the presence of limneid snails and the development of $F$. hepatica. Therefore, the control of this parasitism is very important, not only for its economic impact on cattle and sheep husbandry but also for presenting a public health problem due to its condition of an emerging zoonosis.

Paramphistomum spp. showed prevalence $0.97 \%$ and $2.06 \%$ in cattle and sheep, respectively. Paramphistomum spp., Cotylophoron spp., and Calicophoron spp. are paramfistomids of veterinary importance, responsible for paramfistomosis, diagnosed in cattle, buffaloes, camelids, goats, and sheep [4]. In Colombia, Paramphistomum spp. and
Cotylophorum spp. have been reported in bovine from the Caribbean Coast, as well as in farms from Antioquia [35], Cundinamarca, Casanare, and Meta state [36,37], as well as in sheep from Central Andean region [38]. Therefore, this result is very important since this parasitic genus has not been reported in cattle and sheep of the municipalities under study and could serve to search other studies for this parasitosis. The similarity in morphologic characteristics of paramphistomidae species as well as the lack of expert trematologists becomes an obstacle for epidemiological prevalence studies. Therefore, the employment of genomic sequences is recommended [39]. It is inferred that the low prevalence for this trematode in Encino, Duitama, and Belen municipalities could be associated with the low occurrence of the specific intermediate molluscs hosts for this trematode (Lymnaea genus snails); however, it could be thought that a biological competition between the F. hepatica and Paramphistomum spp. miracidiae by parasitizing intermediate molluscs is the reason for the low prevalence [39].

As for the cestodes group, Moniezia spp. eggs in cattle were very low $(0.97 \%)$ and no differences were found between the three age groups. This result agrees with those reported by Orjuela et al. [18] and Rodríguez-Vivas et al. [21], who demonstrated similar prevalence values. Unlike cattle, the presence of Moniezia spp. eggs in sheep was moderate (7.21\%), but no differences were found between age groups. This result differs with those reported by Pulido-Medellin et al. [24], who demonstrated lower prevalence values $(1.1 \%)$ in sheep. Monieziosis is present in grazing cattle and sheep, especially where infected animals contaminate pastures with the eggs of the cestode. Besides, oribatid mites (intermediate hosts) have to be also present; cysticercoids or larval stages of Moniezia spp. develop in them and in this way, the life cycle is completed, and the infection is maintained [15]. Climate conditions and type of grass also determine the survival of the mites. Wet soils with abundant humus and vegetation permit a better living for these intermediate hosts, in contrast with dry lands where their survival is more difficult [15]. Regarding to nematodes group, parasite genera grouped under the Strongylida order showed highest prevalence values in cattle and sheep (16.5\% and $31.9 \%$ ), respectively, and no differences were found between the age groups. The result agrees with those reported by Pinilla et al. [19] who demonstrated similar prevalence values $(16.3 \%)$ in cattle from Cesar state. However, this result differs with those by Orjuela et al. [18] who reported higher prevalence values $(70.1 \%)$ for Strongylida order in cattle from North Coast of Colombia. This result also differs with other authors, who reported $60.6 \%$ and $73 \%$ prevalence in cattle from Mexico and Peru, respectively [16,21]. In contrast, this result agrees with those reported by Pulido-Medellin et al. [24] who demonstrated similar prevalence values in sheep from Toca municipality, Boyaca. Nevertheless, the result differs with those 
reported by Herrera et al. [40] and Zapata et al. [41] who demonstrated higher prevalence values $(76 \%$ and $86.6 \%$ ), respectively, in sheep from Antioquia state. With respect to Strongyloides spp. showed low prevalence in cattle and sheep (3.8\% and 3.1\%), respectively, and no differences were found between age groups. The result obtained agrees with those reported by Pulido-Medellin et al. [24] who demonstrated similar prevalence in sheep, while the result in cattle differs with those reported by other authors, who demonstrated higher prevalence values in cattle from North Coast of Colombia and Cesar state $[18,19]$, respectively. Probably, the weather conditions during the sampling period are not the most favorable for the transmission of GI nematodes in cattle and sheep. Quiroz et al. [15] showed that climate is an important factor for the presence or absence of nematodes in cattle and sheep. Although there is an adaptation to the temperature factor for the development of free life stages, the humidity is fundamental. Therefore, the regions with the highest rainfall in the tropics are the most favorable for the presentation of GI nematodes. Moreover, the size of the farms, soil and pastures type, deworming, sanitary management, and hygiene conditions in the farms should be considered as a protective factor for the transmission of the nematodes.

\section{Conclusion}

Cattle and sheep in Colombian Northeastern Mountain were infected with helminths and coccidia. The prevalence values of GI parasites were moderate in both species warranting treatment. The presence of $F$. hepatica represents a risk factor to health public. Future studies are required to evaluate the parasitic dynamics throughout the year and the impact on animal production.

\section{Authors' Contributions}

NUD conceived and designed the research. AAF conducted the sample collection. JCPL and AAF processing of samples in the laboratory of parasitology. JCPL carried out the data analysis and writing of the manuscript. All the authors read and approved the submitted version of the manuscript.

\section{Acknowledgments}

The authors thank the University of Santander, Colombia for financial support of this project No. PICF0116756343557EJ. The authors thank the staff of Investigation Research Laboratory of the Parasitology of the Industrial University of Santander, Colombia for their help in the conduction of this project. We also express our gratitude to Dr. Antonio Betancourt for his collaboration in parasitic identification.

\section{Competing Interests} interests.

\section{Publisher's Note}

Veterinary World remains neutral with regard to jurisdictional claims in published map and institutional affiliation.

\section{References}

1. Cordero, C.M. and Rojas, F. (1999) Parasitología Veterinaria. $1^{\text {st }}$ ed. McGraw Hill, España. p323.

2. Charlier, J., Hoglund, J., Samson-Himmelstgorna, G. and Dorny, P. (2009) Gastrointestinal nematode infections in adult dairy cattle: Impact on production, diagnosis and control. Vet. Parasitol., 164(1): 70-79.

3. Becerra, W. (2001). Considerations on sustainable strategies for the control of Fasciola hepatica in Latin America. Rev. Col. Cienc. Pec., 14(1): 28-35.

4. Muro, A. and Ramajo, M. (2002) Paramfistomosis. In: del Campillo, C., Rojo, F.A., editors. Parasitología Veterinaria. McGraw-Hill, España. p225-228.

5. ICA. (2017) Instituto Colombiano Agropecuario. Vigilancia Epidemiológica. Censo Pecuario Nacional-2017. Available from: https://www.ica.gov.co/Areas/Pecuaria/Servicios/ Epidemiologia-Veterinaria/Censos-2016/Censo-2017.aspx . Last accessed on 10-07-2018.

6. Gobernación de Santander. (2017) Municipios del Departamento de Santander. Available from: http://www. santander.gov.co/d/index.php/es/mainmeneldpto/mendepmun2017. Accessed on 12-07-2018.

7. Gobernación de Boyacá. (2017) Municipios del Departamento de Boyacá. Available from: http://www. boyaca.gov.co/d/index.php/es/mainmeneldpto/mendepmun2017. Accessed on 12-07-2018.

8. Thrusfield, M. (2007) Veterinary Epidemiology. $3^{\text {rd }}$ ed. Blackwell Science Ltd., Oxford. p624.

9. Estrada, V., Gómez, M. and Velásquez, L. (2006). The hygiene of cattle and bovine fasciolosis, Medellín and Rionegro, 1914-1970. IATREIA., 19(4): 393-407.

10. Sandoval, E., Morales, G., Ybarra, N., Barrios, M. and Borges, J. (2011) Comparison between two different models of McMaster chambers used for the counting in the diagnosis of nematode infections gastroenteric in ruminants. Zootec. Trop., 29 (4): 495-501.

11. Correa, S., Martínez, Y.L., López, J.L. and Velásquez, L.E. (2016) Evaluation of the modified Dennis technique for the diagnosis of bovine fasciolosis. Biomedica., 36 (1): 64-68.

12. IBM. (2012) SPSS Statistics for Windows, Version 21.0. IBM Corporation, Armonk, New York.

13. Fiel, C., Steffan, P. and Ferreyra, P. (2011) In: Fiel, C., Steffan, P., Ferreyra, P., editors. Diagnóstico más Frecuente de las Parasitosis de los Rumiantes: Técnicas de Laboratorio e Interpretación de Resultados. República de Argentina, Buenos Aires. p131.

14. Urdaneta, F., Urdaneta, A., Parra, A., Chacín, E., Ramírez, R. and Angúlo, F. (2011) Prevalence and degree of infection of gastrointestinal helminths in double purpose cattle herds in Miranda municipality of the state of Zulia, Venezuela. Rev. Cient. FCV-LUZ., 2 (2): 184-193.

15. Quiroz, H., Figueroa, J., Ibarra, F. and López, M., editors. (2011) Epidemiología de Enfermedades Parasitarias en Animales Domésticos. FMVZ UNAM, México. p655.

16. Colina, J., Mendoza, G. and Jara, C. (2013) Prevalence and intensity of gastrointestinal parasitism by 313 nematodes in bovines, Bos taurus, from the Pacanga district (La Libertad, Peru). Rebiol., 33 (2): 76-83.

17. Diaz de Ramírez, A., Justo, J.A., González, M., Piña, E.F. and Ramírez, L.I. (1998) Prevalence of coccidia in bovines of the plains of Monay, Trujillo state, Venezuela. Rev. Cient. FCV-LUZ., 3 (4): 346-353.

18. Orjuela, J., Navarrete, M., Betancourt, A., Roqueme, L., Cortez, E. and Morrison, R. (1991) Health and productivity 
in cattle of the northern coast of Colombia. World. Anim. Rev., 69 (4): 7-14

19. Pinilla, J.C., Flórez, P., Sierra, M., Morales, E., Sierra, R., Vásquez, M.C., Tobon, J.C., Sánchez, A. and Ortiz, D. (2018) Point prevalence of gastrointestinal parasites in double purpose cattle of Rio de Oro and Aguachica municipalities, Cesar state, Colombia. Vet. Parasitol. Reg. Stud. Rep., 12: 26-30.

20. Domínguez, J.L., Rodríguez, R.I. and Honhold, N. (1993) Epizootiology of gastrointestinal parasites in bovines of the state of Yucatan. Veto. Mex., 24 (3): 189-193.

21. Rodríguez-Vivas, R.I., Cob-Galera, L.A. and DomínguezAlpizar, J.L. (2001) Frequency of gastrointestinal parasites in domestic animals diagnosed in Yucatan, Mexico. Rev. Biomed., 12 (1): 19-25.

22. Ensuncho-Hoyos, C., Castellano-Coronado, A., MazaAngulo, L., Bustamante-Yánez, M. and Vergara-Garay, O. (2014) Prevalence and degree of infection of gastrointestinal nematodes in sheep of short hair grazing in four municipalities of Córdoba, Colombia. Rev. Cient. FCV-LUZ., 24 (5): 414-420.

23. Díaz-Anaya, A., Chavarro-Tulcán, G., Pulido-Medellín, M., García-Corredor, D. and Vargas-Avella, J. (2017) Coproparasitological study in sheep grazing in Boyacá, Colombia. Rev. Salud Anim., 39 (1): 1-8.

24. Pulido-Medellín, M., García-Corredor, D., Díaz-Anaya, A. and Andrade-Becerra, R. (2014) Research of gastrointestinal parasites in small sheep farms in the municipality of Toca, Colombia. Rev. Salud Anim., 36 (1): 65-69.

25. Shepelo, P., Gitau, G., Matiku, C., Vanleeuwen, J., Shauna, R., Jeff, W., Fabienne, U. and Omwando, M. (2015) Prevalence of Cryptosporidia, Eimeria, Giardia, and Strongyloides in pre-weaned calves on smallholder dairy farms in Mukurweini district, Kenya. Vet. World., 8(9): 1118-1125.

26. Tamasaukas, R., Agudo, L. and Vintimilla, M. (2010) Pathology of bovine coccidiosis in Venezuela: A review. Rev. Electron. Vet., 11 (7): 1-39.

27. Tomczuk, K., Grzybek, M., Szczepaniak, K., Studzińska, M., Demkowska, M., Roczen, M. and Klockiewicz, M. (2015) Analysis of intrinsic and extrinsic factors influencing the dynamics of bovine Eimeria spp. from central-eastern Poland. Vet. Parasitol., 214(1-2): 22-28.

28. Rojas, D. and Cartín, J. (2016) Prevalence of Fasciola hepatica and economic losses associated with the confiscation of livers in three class A slaughterhouses in Costa Rica. Agron. Costarric., 40 (2): 53-62.

29. Soca-Pérez, M., Giupponi-Cardoso, P., López-Vigoa, O., Sanavria, A., Sánchez-Santana, T. and Labrada-Vázquez, A. (2016) Prevalence of Fasciola hepatica in cows in pasture during the dry season. Forages Pastures., 39 (4): 281-285.
30. Ticona, D., Chávez, A., Casas, G., Chavera, C.A. and Li, E. (2010) Prevalence of Fasciola hepatica in bovines and sheep from Vilcashuamán, Ayacucho. Rev. Invest. Vet. Peru., 21 (2): 168-74.

31. Gauta, J., Perez, A., Lecuna, J., Garcia, M., Aguirre, A., Armas, S. and Quijada, J. (2011) Prevalence of Fasciola hepatica in high-altitude livestock in Bailadores, Mérida, Venezuela. Rev. Electron. Vet., 12 (11): 1-8.

32. Estupiñán, J., Pabuena, J., Castro, C., Morales, E., Vásquez, M., Calle, M. and Sierra, R. (2016) Determination of the prevalence of Fasciola hepatica in bovines from Rio de Oro and Aguachica, Cesar. Fac. Cienc. Health UDES J., 3 (S1): 19 .

33. Recalde-Reyes, D., Padilla, L., Giraldo, M., Toro, L., Gonzalez, M. and Castaño, J. (2014) Prevalence of Fasciola hepatica, in humans and cattle in the department of Quindío -Colombia 2012-2013. Infectio., 18 (4): 153-157.

34. Valderrama, A. (2016) Prevalence of fascioliasis in polygastric animals of Peru, 1985-2015. Rev. Med. Vet., 32 (2): 121-129.

35. Bedoya, J., Hurtado, Y., Pérez, J., Solano, S., Úsuga, V., Vanegas, M., Gómez, C., López, J. and Velásquez, L. (2012) First registration of fascioliasis and paramfistomosis foci in double purpose cattle, Gómez Plata, Antioquia, Colombia. Facts. Microbiol., 3 (1): 31-39.

36. Alarcon, P. and Velásquez, L. (2009) Morphological description of Cotylophoron cotylophorum (Digenea: Paramphistomidae) found in bovines of Rio Negro, Antioquia, Colombia. Rev. Colomb. Science. Pecua., 22 (2): 168-177.

37. López, J. and Velásquez, L. (2012) Cotylophoron panamensis (Digenea: Paramphistomidae) in bovines of Meta and Guaviare, Colombia, Act. Biol. Colomb., 17 (2): 421-430.

38. Galvis, J.D., Parra, G.D. and Hernández de Galvis, A.L. (1984) Evidence of ovine paraphysiomyomiasis in Colombia. Rev. ICA., 19: 413-416.

39. Zintl, A., García-Campos, A., Trudgett, A., Chryssafidis, A., Talavera-Arce, S., Fu, Y., Egan, S., Lawlor, A., Negredo, C., Brennan, G., Hanna, R., De Waal, T. and Mulcahy, G. (2014) Bovine paramphistomes in Ireland. Vet. Parasitol., 204(3-4): 199-208.

40. Herrera, L., Ríos, L. and Zapata, R. (2013) Frequency of infection by gastrointestinal nematodes in sheep and goats of five municipalities of Antioquia. Rev. MVZ Córdoba., 18 (3): 3851-3860.

41. Zapata, R., Velásquez, R., Herrera, L., Ríos, L. and Polanco, D. (2016) Prevalence of gastrointestinal nematodes in sheep and goat production systems under confinement, semi-confinement and grazing in municipalities of Antioquia, Colombia. Rev. Invest. Vet. Peru, 27 (2):344-354. 